\title{
Utilitarismo repaginado: uma faceta do neoliberalismo contemporâneo
}

\author{
Repaginated utilitarism: a facet of contemporary neoliberalism
}

Utilitarismo repaginado: una faceta del neoliberalismo contemporáneo

Gicele Weinheimer ${ }^{1}$; Fernanda Wanderer ${ }^{2}$

\section{RESUMO}

$\mathrm{O}$ artigo apresenta resultados de uma investigação que teve por objetivo identificar sentidos que alunos do Ensino Médio (EM) atribuem à relevância do utilitarismo do conhecimento escolar. As bases teóricas advêm dos estudos de Michel Foucault e seus comentadores, como Sibilia, Ball e Dardot e Laval. A parte empírica foi realizada em uma escola pública da região metropolitana de Porto Alegre (RS), no ano letivo de 2017. O material escrutinado é composto por questionários respondidos pelos discentes que frequentavam a última etapa da educação básica sobre suas concepções a respeito da escola e do EM na atualidade. A análise mostrou que a escola ainda pode ser pensada enquanto uma maquinaria capaz de produzir alunos para uma determinada função social, voltada para o mercado de trabalho. Ao mesmo tempo, tem sido capturada pela perspectiva mercadológica, incitando os estudantes a agirem de modo a tornarem-se empresários de si mesmos, realizando investimentos a partir de cálculos de interesses que lhes garantam um lugar de destaque no cenário competitivo.

Palavras-chave: Ensino Médio; utilitarismo; neoliberalismo.

\begin{abstract}
The article presents results of an investigation that aimed to identify meanings that high school students attribute to the relevance of the utilitarianism of school knowledge. The theoretical bases come from the studies of Michel Foucault and his commentators, such as Sibilia, Ball and Dardot and Laval. The empirical part was carried out in a public school in the metropolitan region of Porto Alegre (RS), in the academic year of 2017. The material scrutinized consists of questionnaires answered by students who attended the last stage of basic education about their conceptions about the school and high school today. The analysis showed that the school can still be thought of as a machinery capable of producing students for a given social function, aimed at the job market. At the same time, it has been captured by the marketing perspective, encouraging students to act in order to become entrepreneurs of their own, making investments based on calculations of interests that guarantee them a prominent place in the competitive scenario.
\end{abstract}

Keywords: High school; utilitarianism; neoliberalism.

\section{RESUMEN}

El artículo presenta los resultados de una investigación que tuvo como objetivo identificar los significados que los estudiantes de secundaria atribuyen a la relevancia del conocimiento escolar utilitario. Las bases teóricas provienen de los estudios de Michel Foucault y sus comentaristas, como Sibilia, Ball y Dardot y Laval. La parte

\footnotetext{
${ }^{1}$ Mestra em Educação e Licenciada em Filosofia. Integra a Linha de Pesquisa Estudos Culturais em Educação da Universidade Federal do Rio Grande do Sul (UFRGS), Porto Alegre/RS - Brasil. E-mail: gicele.weinheimer@gmail.com

2 Doutora e Mestra em Educação. Professora do Programa de Pós-Graduação em Educação da Universidade Federal do Rio Grande do Sul (UFRGS), Porto Alegre/RS - Brasil. E-mail: fernandawanderer@gmail.com
} 
empírica se llevó a cabo en una escuela pública de la región metropolitana de Porto Alegre (RS), en el año académico de 2017. El material analizado consiste en cuestionarios respondidos por estudiantes que cursaban la última etapa de educación básica sobre sus concepciones sobre la escuela. y la escuela secundaria hoy. El análisis mostró que todavía se puede pensar en la escuela como una maquinaria capaz de producir estudiantes para una función social determinada, dirigida al mercado laboral. Al mismo tiempo, ha sido captado por la perspectiva del marketing, incentivando a los estudiantes a actuar para convertirse en emprendedores propios, realizando inversiones basadas en cálculos de intereses que les garanticen un lugar destacado en el escenario competitivo.

Palabras clave: Escuela secundaria; utilitarismo; neoliberalismo.

\section{INTRODUÇÃO}

O artigo discute um tema presente na esfera educacional contemporânea: a utilidade do conhecimento escolar, em especial, no Ensino Médio. São variadas as enunciações provenientes de documentos oficiais, pesquisas acadêmicas, educadores e alunos expressando a relevância da escola propiciar um ensino "útil" aos estudantes. Em efeito, documentos que orientam o Ensino Médio, como a Base Nacional Comum Curricular (BNCC) e as Diretrizes Curriculares Nacionais para o Ensino Médio afirmam, de forma recorrente, que uma das funções da escola é preparar os alunos para conviverem em sociedade, para resolverem problemas do dia-a-dia e, de forma mais enfática, para o mercado de trabalho. Na BNCC (BRASIL, 2020, p.466) é expresso que a escola deve, entre outras questões: "garantir a contextualização dos conhecimentos, articulando as dimensões do trabalho, da ciência, da tecnologia e da cultura" e, além disso, "viabilizar o acesso dos estudantes às bases científicas e tecnológicas dos processos de produção do mundo contemporâneo, relacionando teoria e prática ou o conhecimento teórico à resolução de problemas da realidade social, cultural ou natural".

Outra reverberação do utilitarismo nas instituições escolares do Ensino Médio pode ser visualizada nas Diretrizes Curriculares Nacionais para o Ensino Médio (BRASIL, 2018). A flexibilização curricular é posta como um atrativo, um modo de manter ou trazer o aluno de volta aos bancos escolares, evitando a evasão e qualificando essa etapa da educação. No texto das Diretrizes, mais uma vez, observa-se uma forte referência à utilidade do conhecimento escolar, como evidenciam alguns dos princípios que devem orientar a oferta e organização do Ensino Médio no Brasil: "II - projeto de vida como estratégia de reflexão sobre trajetória escolar na construção das dimensões pessoal, cidadã e profissional do estudante"; "VII - diversificação da oferta de forma a possibilitar múltiplas trajetórias por parte dos estudantes e a articulação dos saberes com o contexto histórico, econômico, social, científico, ambiental, cultural local e do mundo do trabalho" e "IX - indissociabilidade entre teoria e prática no processo de ensino-aprendizagem" (BRASIL, 2018, p.2).

Além dos documentos oficiais, um conjunto de pesquisas, como as realizadas por Souza (2011), Lenoir (2016) e Villar (2013), evidenciam o quanto a dimensão da utilidade do conhecimento escolar se faz presente nas discussões da área da Educação. Souza (2011) analisa os conceitos "sociedade da informação" e "sociedade do conhecimento" a partir das transformações suscitadas pelo capital no mundo do trabalho. A investigação mostra a estreiteza do olhar neoliberal sobre o acesso à informação e à produção de conhecimentos, enfatizando-os a partir do ponto de vista utilitarista, buscando aumentar a produtividade e a competitividade organizacional. Conforme a autora, "por mais fabulosas que sejam as possibilidades de acesso à informação e ao conhecimento, estes não são distribuídos equitativamente para todos, pois sofrem os limites impostos pelo sistema-capital" (IBIDEM, p. 7). Isso evidenciaria o viés utilitarista propagado pela lógica econômica, "em que se 
destaca a busca de habilidades e competências, visando à produtividade e a competividade" (IBIDEM, p. 8).

A investigação de Lenoir (2016) mostra como as Ciências Humanas têm sido diretamente influenciadas pelo utilitarismo, modificando suas finalidades em prol de uma lógica mercantilista. Conforme pontuou Lenoir (2016, p.160), "um mal se espalha pelo mundo ocidental nas últimas décadas como um incêndio. Esse mal tem um nome: utilitarismo!". Apoiado em Caillé, Lazzeri e Senellart, o autor empreende uma crítica a esse modo de se conduzir, ao indivíduo que busca satisfazer os interesses mesquinhos e individualistas, insuflando a ideia da dimensão econômica como "o único vetor do comportamento do humano" (IBIDEM, p. 161). Seguindo sua linha de pensamento, ele assevera que "as universidades ocidentais têm se curvado às exigências da comercialização do saber" (IBIDEM, p.162), conduzindo os alunos à Universidade com vistas na obtenção de um diploma que Ihes garantiria o sucesso profissional, uma vida economicamente confortável.

A pesquisa de Villar (2013) apresenta uma sistematização dos fundamentos filosóficos da educação profissional, visando contribuir com a história da educação. O autor faz uma análise dos conceitos de "utilidade" e "utilitarismo" sob diferentes perspectivas teórico-filosóficas, assim como da sua manifestação histórica no âmbito da educação profissional. A partir disso, ele assevera que o utilitarismo "teria sido influenciado pela relação custo/benefício aplicada às mercadorias, sendo mais um sintoma da reificação do trabalhador e da redução da força de trabalho a uma mercadoria" (VILLAR, 2013, p. 131). Isso posto, poder-se-ia dizer que a supracitada modalidade de ensino "teria passado de uma tendência liberal redentora de caráter profilático para um Liberalismo tecnicista de caráter utilitarista. Entre o encontrar um lugar para os pobres no sistema produtivo, até a manutenção dos pobres no seu lugar" (VILLAR, 2013, p.131).

A investigação que realizamos, consolidada no presente artigo, teve por objetivo identificar sentidos que alunos do Ensino Médio atribuem à relevância do utilitarismo do conhecimento escolar. Pautadas nas teorizações foucaultianas, compreendidas como ferramentas para operarmos sobre os materiais empiricamente produzidos, podemos dizer que nos afastamos dos trabalhos acima referidos. Do mesmo modo, assemelhamo-nos quanto às problematizações suscitadas em torno do utilitarismo.

\section{METODOLOGIA}

A parte empírica da pesquisa foi realizada em uma Escola Estadual localizada na cidade de Arroio dos Ratos, município pertencente à região Metropolitana de Porto Alegre, onde uma das autoras atua como professora. O material escrutinado é composto pela compilação de questionários respondidos discursivamente pelos discentes que frequentavam a última etapa da educação básica na mesma instituição de ensino, no ano letivo de 2017. Deve-se pontuar que, antes da investigação iniciar, obtivemos as assinaturas dos Termo de Assentimento da Instituição e do Termo de Consentimento Livre e Esclarecido.

Elaboramos um questionário contendo perguntas sobre a escola e o Ensino Médio que foram impressas e entregues aos alunos do regular diurno que aceitaram participar de nosso estudo. Esse processo foi concomitante ao andamento das aulas, com a devida permissão da direção e do professor regente, não necessitando mais do que um período de cinquenta minutos para a aplicação dos mesmos. As questões foram: 1. Para você, qual a função do Ensino Médio? 2. Descreva o que você pensa sobre o Ensino Médio ter como foco a formação técnica e profissionalizante. 3. Você concorda 
com a Proposta do Governo que pretende reformar o Ensino Médio de todas as escolas do país? Por quê? 4. Se você tivesse que escolher hoje uma única área do conhecimento para aprofundar seus estudos, você saberia qual? Por quê? Dos 302 alunos regularmente matriculados naquele ano, 160 responderam ao questionário, correspondendo a 53\% do total. Isso evidencia o caráter voluntário da pesquisa, resguardando ao aluno o direito de não participar. O cabeçalho do questionário continha informações a respeito da voluntariedade, do anonimato e do sigilo das respostas, restringindo o seu uso ao âmbito acadêmico. Corroborando as sugestões de Peixoto, permitiu-se ao aluno a escolha de, "a qualquer instante, poder se recusar a participar da pesquisa" (2017, p.155).

Eram tempos de greve. Muitos professores deixaram de ir regularmente à escola, abrindo brechas na carga horária das turmas. Devido ao aumento das horas vagas, o movimento discente nessa instituição foi diminuído e, consequentemente, a colaboração na produção do material empírico. 0 transporte escolar também foi um dificultador para o baixo número de alunos nos dias de aplicação dos questionários, pois muitos precisavam sair cedo de suas casas, passando horas ociosas, às vezes tendo apenas um ou dois períodos de aulas, podendo retornar somente no horário da saída.

Nas turmas em que foram aplicados os questionários, a dinâmica foi praticamente a mesma. A produção dos questionários foi conduzida pela primeira autora do artigo que era professora de Filosofia na escola e já conhecia os alunos e as demais professoras. Inicialmente, foi solicitado auxílio às educadoras que cedessem um ou dois períodos de suas disciplinas com as turmas. Ao entrar na sala de aula e cumprimentar os discentes, explicava-se sobre a pesquisa e lia-se o cabeçalho do questionário. Na sequência, explicava-se que a participação não era obrigatória, que haveria sigilo em relação à identidade dos voluntários e que todas as respostas seriam utilizadas somente no âmbito acadêmico.

Escolhemos a análise do discurso na perspectiva foucaultiana como estratégia para operarmos sobre o material empírico. Foucault nos inspira a escrutinar os sistemas linguísticos, que põem enunciados em movimento, através do método arqueológico (VEIGA-NETO, 2007). Esse método "não é nada além e nada diferente de uma reescrita: isto é, na forma mantida da exterioridade, uma transformação regulada do que já foi escrito. Não é o retorno ao próprio segredo da origem; é a descrição sistemática de um discurso-objeto" (FOUCAULT, 2009, p. 158). Conforme o filósofo, "só é possível estabelecer um sistema linguístico (se ele não é construído artificialmente) utilizando um corpus de enunciados ou uma coleção de fatos de discurso" (FOUCAULT, 2008a, p, 92). Foucault diz que uma língua "constitui sempre um sistema de enunciados possíveis; é um conjunto finito de regras que autoriza um número infinito de performances" (FOUCAULT, 2008a, p. 92). O discurso, todavia, é sempre finito e limitado pelas sequências linguísticas que o constituem (IBIDEM).

Analisando o conceito "linguagem", Castro (2009, p.251) sugere que essa palavra ganha destaque no cenário foucaultiano pelo seu uso e pela sua prática, "no contexto de outras práticas que não são de caráter linguístico". O que importa é o que se faz com a linguagem, tomada enquanto fabricada e fabricante. A isso Foucault chamou de prática discursiva, "um conjunto de regras anônimas (...) que definiram, em uma dada época e para uma determinada área social, econômica geográfica ou linguística, as condições de exercício da função enunciativa" (FOUCAULT, 2009, p. 133). O que está em jogo aí são as regras que permitem um enunciado ser proferido. Como a prática discursiva é determinada pelo contexto no qual está imersa, sendo, ao mesmo tempo, produtora e produzida, o enunciado também estará limitado a esse recorte histórico, pois traz consigo as marcas que o tornaram possível, sendo considerado "desde o ponto de vista de suas condições de existência" 
(CASTRO, 2009, p. 136). De modo semelhante, a enunciação pode ser compreendida como uma expressão discursiva, uma fala diretamente conectada ao contexto no qual foi fabricada. Porém, diferentemente do enunciado, deve-se ressaltar que a enunciação é "um acontecimento que não se repete; tem uma singularidade situada e datada que não se pode reduzir" (VEIGA-NETO; RECH, 2015, p. 114).

Porquanto, na perspectiva à qual estamos vinculadas, tem-se como pressuposto "que a verdade é uma invenção, uma criação. Não existe a 'verdade', mas sim 'regimes de verdade', isto é, discursos que funcionam na sociedade como verdadeiros" (PARAÍSO, 2014, p. 29). Fazendo reverberar a relação exterioridade - monumento posta por Foucault, Veiga-Neto (2007, p.104) alerta para a importância de se ler o texto "no seu volume e externalidade (monumental) e não na sua linearidade e internalidade (documental)". Ao se fazer isso, está-se buscando não uma verdade, mas "os contatos de superfície que ele mantém com aquilo que o cerca" (IBIDEM, p. 105).

Considerando as reflexões até aqui desenvolvidas, asseveramos que os discentes, ao escreverem suas respostas, proferiram enunciações, compreendidas enquanto falas. Assim, importa destacar que a ferramenta da análise do discurso posta em operação foi a enunciação. Na próxima seção, essas falas serão apresentadas ao longo do texto, em itálico, como citações curtas, auxiliando-nos a instaurar costuras analíticas, tendo em vista os aportes teórico-metodológicos por nós elegidos.

\section{UTILITARISMO COMO UM DIAPASÃO MODERNO REGULADO AOS INTERESSES CONTEMPORÂNEOS}

Debruçando-nos sobre o material empírico, encontramos uma recorrência nas respostas dos alunos que nos remeteu à escola moderna e ao seu modus operandi. Isso possibilitaria asseverar que algumas características dos tempos passados permanecem vivas nesses espaços institucionais, embora tenham adquirido uma outra roupagem. Apesar de estarmos em pleno século XXI, a escola ainda pode ser pensada enquanto uma maquinaria capaz de produzir alunos para uma determinada função social, voltada para o mercado de trabalho. Os excertos selecionados corroboram essa linha de pensamento: "O aluno já sai capacitado para o mercado de trabalho. Por outro lado, o aluno seria 'obrigado a fazer o curso técnico que a escola oferecer"; "Para arrumar um emprego. Porque sem estudo não se consegue um bom emprego"; "Desenvolver o conhecimento dos alunos, para que saiam daqui prontos para o mercado de trabalho"; "O governo quer deixar as escolas mais preparatórias para os alunos".

A primeira resposta traz a ideia de que, se o ensino técnico for efetivado no nível médio, o aluno já sairia capacitado para o mercado de trabalho. Mas ficaria preso à oferta de cada escola, sendo obrigado a fazer aquilo que estiver disponível. A partir dessa enunciação, evidencia-se que o objetivo do governo em instaurar o ensino técnico denota uma preocupação com a qualificação do aluno, preparando-o para o mundo mercadológico. As duas subsequentes reforçam a primeira, destacando a função da escola em preparar os alunos para o mercado de trabalho, acrescentando que "sem estudo não se consegue um bom emprego". Aqui há uma nítida vinculação entre horas de estudo e aquisição de um bom trabalho, sendo a primeira posta como condição necessária à segunda. E como se pode perceber na última resposta selecionada, o governo quer conferir um caráter ainda mais preparatório para a instituição, produzindo alunos mais eficientes para um fim específico. 
Pautados em uma perspectiva de inspiração foucaultiana, muitos autores têm explorado o universo escolar contemporâneo. Entre esses, há uma concordância no que se refere ao caráter não natural dessa instituição. Ela teria sido criada a partir de uma necessidade específica produzida em um determinado contexto sócio-histórico. Conforme Varela e Uria (1992), a escola é um local onde as infâncias pobres podiam se refugiar, livrando-se do ambiente miserável no qual estavam inseridas. Isso porque havia uma burguesia em ascensão que se preocupava com o bem-estar dessa população em situação de risco, inserindo-a em um programa escolar engendrado especialmente para ela. $\mathrm{O}$ que se pretendia era a transformação paulatina de tábulas rasas em bons trabalhadores fabris. A partir disso, evidencia-se o recorte temporal balizado pela dupla: o período moderno. Se a escola é uma invenção da sociedade moderna, ela não é uma instituição dada a priori.

Sibilia (2012), corroborando essa ideia, discute o modelo escolar à semelhança de uma máquina, relação estabelecida inicialmente por Foucault (2009a) no livro Vigiar e Punir. Segundo a autora, a escola surgiu de uma necessidade: "transformar a carne tenra das crianças num ingrediente adequado para alimentar as engrenagens vorazes da era industrial" (SIBILIA, 2012, p. 29). Entretanto, os tempos são outros. A indústria fabril não é mais o foco da escolarização. Na atualidade, a função se deslocou, mas o terreno de aragem não foi abandonado. O mercado de trabalho continua a direcionar os trabalhos escolares, como apontam os excertos trazidos dos questionários.

Esse panorama contemporâneo é também analisado por Sibilia (2012), que percebe uma entronização do modelo empresarial nas instituições em geral, permitindo o espraiamento da competitividade inclusive no âmbito escolar. Agora, os comportamentos são medidos por "parâmetros exclusivamente mercadológicos, que enfatizam a capacidade de diferenciação de cada indivíduo na concorrência com os demais" (IBIDEM, p. 46). Tendo isso em vista, pode-se dizer que as necessidades sociais mudaram, mas são elas que continuam a influenciar os direcionamentos das vidas escolares.

Pensando no termo "usuário" empregado por Sibilia ao se referir ao espectador contemporâneo, trazemos aqui mais alguns resquícios modernos que adquiriram outro viés nos nossos tempos. Perscrutando a introdução da terceira versão da BNCC, nota-se o uso recorrente de um verbo específico, posto enquanto competência geral a ser desenvolvida na educação básica: o "utilizar". Esse verbo nos remete a uma possível retomada contemporânea do princípio da utilidade, engendrado na modernidade pelo filósofo Jeremy Bentham (1984). Todavia, esse princípio condutor de condutas parece ter sofrido algumas alterações fundamentais ao longo do tempo, mostrando-se maleável conforme a variação dos interesses das sociedades que estão a produzi-lo. Os excertos selecionados apontam nessa direção: "Você vai se especializar só nas matérias realmente importantes para seu emprego, sem aplicar matérias sem muita importância"; "É bom para os alunos que poderão eliminar matérias indesejadas e que ele não vai usar"; "Tem muitas matérias que a gente estuda que, para mim, tipo, não têm importância"; "Depende de qual matéria iria aumentar, porque algumas são desnecessárias"; "O aluno ia estudar apenas o que vai servir para o seu curso ou faculdade que virá em seguida"; "Querem fazer com que os jovens aprendam apenas o necessário"; " Fornece conhecimentos, que vão ser usados no meu futuro".

Com a reforma, os alunos têm a ideia de que vão poder escolher as disciplinas mais importantes para o seu futuro acadêmico ou profissional, pois algumas são vistas como irrelevantes: "se especializar só nas matérias realmente importantes para seu emprego, sem aplicar matérias sem muita importância". O que se pode evidenciar nas falas discentes é uma necessidade de se instaurar um cálculo de interesses pessoal que garanta o sucesso de cada um no futuro, principalmente no mercado 
de trabalho, com a obtenção de lucro. Para isso, matérias indesejadas deveriam ser eliminadas por falta de usabilidade, focando o estudo apenas nas necessárias: "eliminar matérias indesejadas e que ele não vai usar". A reforma poderia facilitar a especialização do aluno naquilo que lhe interessa, que Ihe importa, que lhe servirá futuramente, excluindo todas as matérias inúteis e sem aplicação futura. Caberia à escola a tarefa de fazer os jovens aprenderem apenas as coisas necessárias, fornecendo conhecimentos que serão usados no futuro. Como se pode perceber, não são apenas ações e artefatos que caem na mira do cálculo utilitarista, mas também pessoas. E quanto mais interessantes elas forem aos outros, principalmente ao mercado, mais bem colocadas estarão no ranking do desempenho, gerando lucro e colaborando para a manutenção da nova razão do mundo.

Bentham (1984) abre o escrito Uma introdução aos princípios da moral e da legislação dizendo que se debruçará sobre o que ele chama de "princípio da utilidade". O ponto de partida sob o qual devem ser pautados os modos de condução humanos pode ser compreendido como aquilo que "aprova ou desaprova qualquer ação, segundo a tendência que tem de aumentar ou a diminuir a felicidade da pessoa cujo interesse está em jogo" (BENTHAM, 1984, p. 4). No primeiro capítulo da obra, Bentham aponta a dor e o prazer como os dois senhores soberanos que sujeitam nossas vidas em todos os momentos. Esses senhores, segundo o filósofo, governam tudo o que fazemos, dizemos e pensamos. Sob o crivo da dor e do prazer, constitui-se um critério que serve para avaliar moralmente as nossas ações. O que se deve buscar é uma ação benéfica que possibilite a felicidade ao maior número de pessoas possível. Percebe-se aí uma conexão com o hedonismo clássico, fazendo do prazer um mobilizador dos seres vivos, conforme sugere Nicola Abbagnano (2014) em seu Dicionário de Filosofia.

Giovanni Reale e Dario Antisseri (2007) também observam essa ressonância hedonista na perspectiva utilitarista. No quinto volume da História da Filosofia, esses filósofos analisam o termo "utilitarismo" enquanto um modo de pensar o bem identificado com o útil (REALE; ANTISSERI, 2007). Segundo seu olhar específico sobre a obra de Bentham, os italianos sugerem que o utilitarismo é definido como aquilo que é capaz de provocar prazer ou suscitar vantagem. Em relação ao "útil", eles o apresentam como aquilo que tende a minimizar a dor e maximizar o prazer. Isso posto, pode-se estabelecer uma aproximação do utilitarismo ao hedonismo tradicional. Retomando essa relação, Reale e Antisseri acrescentam: "a moral, na perspectiva de Bentham, configura-se como espécie de hedonismo calculado, escrupulosamente atento à avaliação das características do prazer" (2007, p. 302). Assim, quando se julga moralmente uma ação, buscando o prazer e recusando a dor, o que entra em cena é a felicidade, associando-se o prazer àquilo que é bom, e a dor, àquilo que é mau. "Essa é a moral utilitarista: todo indivíduo sempre persegue o que julga ser sua felicidade, ou o estado de coisas em que se dê a maior felicidade e a mínima dor" (IBIDEM, p. 304). O que parece estar em jogo no utilitarismo é um critério moral capaz de possibilitar a felicidade a um maior número de pessoas. $A$ ênfase, nesse caso, estaria direcionada para um caráter social e não meramente individual, o que beneficiaria toda uma coletividade.

Auxiliando-nos a problematizar o utilitarismo, agora na contemporaneidade, citamos Silva, Silva e Vasques (2018). Os autores tentam mapear elementos que os auxiliem a pensar o processo de escolarização atual, relacionando políticas curriculares ao que eles chamam de financeirização da vida. Para isso, eles percebem uma necessidade de empregar um aporte crítico, explorando o conceito de "classe social", além das teorizações foucaultianas. Porquanto, segundo eles, não há como deixar de analisar nos nossos dias "a intensificação das desigualdades sociais que o capitalismo continua a engendrar" (IBIDEM, p. 6). Muitas dessas desigualdades seriam provocadas pelo neoliberalismo, 
pensado enquanto "uma racionalidade orientadora das vidas contemporâneas" (IBIDEM, p. 8). Por ser uma razão que tenta direcionar os modos de vida em todas as partes do globo, ela tem uma pretensão universalizante, organizando "não apenas a ação dos governantes, mas até a própria conduta dos governados" (DARDOT; LAVAL, 2016, p. 17).

Enquanto modelo a ser seguido, as prescrições neoliberais são incorporadas a muitos Estados mundiais, ditando regras de conduta, em relação a si e aos outros. Uma reverberação disso pode ser visualizada na reforma do Ensino Médio insuflada pelo governo de Michel Temer. Conforme pontuam Silva, Silva e Vasques (2018), a escola contemporânea tem servido de espaço à difusão do modelo empresarial, o que tornaria a educação uma mercadoria, e os alunos, os seus clientes. Tendo por base as políticas de avaliação em larga escala e o documento normativo que define as aprendizagens discentes essenciais que deverão ser desenvolvidas nas etapas da educação básica, esses autores também percebem aí "uma visão utilitarista e mercadológica da aprendizagem" (IBIDEM, p. 18).

Outro autor que também aborda o cálculo utilitarista na atualidade educacional é Stephen Ball (2014). O autor sugere que o neoliberalismo é capaz de metamorfosear as relações sociais em meros cálculos de interesse, resguardando a lógica do mercado, produzindo "professores e alunos responsáveis e empreendedores" (BALL, 2014, p. 64). Uma necessidade de cálculo contínuo faz-se presente, buscando-se o aperfeiçoamento, a autopromoção e o lucro disso advindo. Sair-se melhor do que os outros, todos concorrentes em potencial: eis o jogo contemporâneo. Empresários responsáveis por seu sucesso ou fracasso, uma vida em forma de negócio: narcisistas entretidos com seus monstros pessoais.

No livro A nova razão do mundo, Dardot e Laval (2016) defendem a tese que o neoliberalismo é a razão do capitalismo contemporâneo, uma racionalidade que coloca a empresa como um modelo de conduta, fazendo da concorrência a sua norma. Conforme os autores, "o neoliberalismo pode ser definido como o conjunto de discursos, práticas e dispositivos que determinam um novo modo de governo dos homens segundo o princípio universal da concorrência" (IBIDEM, p. 17). A partir disso, enfatizam que o neoliberalismo é um sistema normativo que tem influenciado não só as condutas de indivíduos, mas também práticas governamentais, políticas institucionais e estilos de gerenciamentos (IBIDEM). Enquanto um modelo universalizante, "hospitais, escolas, universidades, tribunais e delegacias são considerados empresas da alçada das mesmas ferramentas e das mesmas categorias" (IBIDEM, p. 313).

No âmbito escolar, o Estado agiria em prol dessa lógica mercantilista, fazendo um reajuste nas instituições a fim de torná-las semelhantes à empresa, "criando, dentro do setor público, as condições econômicas e extraeconômicas necessárias para que os negócios possam operar" (IBIDEM, p. 73). Desse modo, pode-se dizer que a escola, enquanto instituição socialmente engendrada, tem sido capturada por essa perspectiva mercadológica, incitando os alunos a "calcular e maximizar seus interesses, perseguindo lógicas mais individuais num contexto de concorrência mais radical entre eles" (DARDOT; LAVAL, 2016, p. 243). Impelidos pela racionalidade neoliberal, os discentes acabam agindo de modo a tornarem-se empresas de si mesmos, realizando investimentos a partir de cálculos de interesse que lhes garantam um lugar de destaque no cenário competitivo.

Para isso, buscam o conceito de "racionalidade política" cunhado por Foucault quando ele tratava da governamentalidade. Conforme os autores, uma racionalidade política é uma racionalidade governamental, pois uma razão governamental envolve os tipos de racionalidade que são mobilizados por uma administração Estatal para conduzir as condutas humanas (DARDOT; LAVAL, 2016). Por 
isso, o neoliberalismo pode ser compreendido como um modo de conduzir os indivíduos na direção da concorrência generalizada. A empresa é vista como um modelo a ser incorporado pelas sociedades, levando a concorrência a todas as esferas, inclusive institucionais. Pensando no deslocamento do liberalismo moderno ao neoliberalismo contemporâneo, a dupla francesa pontua que

A gestão da população muda de método e significado. Enquanto no período fordista a ideia predominante era, segundo a expressão consagrada, a "harmonia entre eficácia e progresso social", hoje, no contexto de um capitalismo nacional, essa mesma população é percebida apenas como um "recurso" à disposição das empresas, segundo uma análise em termos de custo-benefício. (DARDOT; LAVAL, 2016, p. 284)

O que se percebe é um uso da população pelo mercado e uma tentativa dos Estados de aumentarem a empregabilidade de seu povo, diminuindo os custos administrativos da máquina pública. Porquanto, o indivíduo passa a cuidar de si mesmo, responsabilizando-se pela constância do próprio aperfeiçoamento. Ao Estado, cabe a garantia da livre concorrência. Ele não precisa mais intervir na economia por meio de legislações específicas, a fim de garantir a felicidade ao maior número de pessoas, como acontecia nos tempos de Bentham. A máxima contemporânea passa a ser o cuidado de si mesmo, o que possibilita ao indivíduo uma busca constante pelo aumento de produtividade e eficiência. Isso porque "todas as suas atividades devem assemelhar-se a uma produção, a um investimento, a um cálculo de custos. A economia torna-se uma disciplina pessoal" (DARDOT; LAVAL, 2016, p. 331). Tendo isso em vista, pode-se asseverar que o eixo é deslocado da coletividade para a individualidade, fazendo do utilitarismo um propulsor do âmbito privado. Nesse sentido, rastros do utilitarismo podem ser percebidos na contemporaneidade. O neoliberalismo, enquanto lógica de ação preponderante, faz com que o cálculo de interesses se torne uma regra de conduta, cooptando as práticas individuais, inclusive as escolares.

Contudo, será que as necessidades de uma sociedade permanecem as mesmas ao longo dos anos ou se modificam conforme os interesses do Estado e/ou do mercado? Quem estaria apto a estabelecer o que é útil e o que não é, e sob quais critérios? Nuccio Ordine, na introdução do livro $A$ utilidade do inútil, sugere que a busca desenfreada pela obtenção do lucro tem abalado certas instituições, como as escolares, acadêmicas e de pesquisa. Isso também estaria ocorrendo com disciplinas humanas e científicas, que deveriam ser tratadas "independentemente da capacidade de produzir ganhos imediatos ou benefícios comerciais" (ORDINE, 2016, p. 9-10). Cooptadas pela lógica neoliberal, essas instituições e disciplinas têm sido tratadas "como um luxo supérfluo, como um obstáculo perigoso" (IBIDEM, p. 13), devendo ser desprezadas pela incapacidade de produzirem lucro.

Sob o jugo do neoliberalismo, pode-se dizer que as coisas ainda são balizadas a partir de um cálculo de interesses. A partir disso, pode-se dizer que o utilitarismo de Bentham permanece na atualidade, embora com outra roupagem, permitindo que o mundo continue a ser avaliado por essa lente. Conforme sugeriu Ordine,

No universo do utilitarismo, um martelo vale mais que uma sinfonia, uma faca mais que um poema, uma chave de fenda mais que um quadro: porque é fácil compreender a eficácia de um utensílio, enquanto é sempre mais difícil compreender para que podem servir a música, a literatura ou a arte. (ORDINE, 2016, p. 12).

Os excertos trazidos constatam a perspectiva apontada por Ordine: "Linguagens, porque pra mim vai ser muito útil"; "Existem matérias desnecessárias onde não aprendemos o que realmente precisamos, e assim perdemos tempo"; "Poderíamos eliminar as matérias desnecessárias"; "Matemática, porque tem muitas coisas para aprofundar na matéria; e com essa matéria podemos fazer muitas coisas". 
Depreende-se das enunciações que as disciplinas consideradas importantes pelos alunos são aquelas que os auxiliariam de algum modo no desenvolvimento profissional ou acadêmico, como sugere a seguinte resposta: "Linguagens, (...) pra mim vai ser muito útil". Todas as outras são vistas como desnecessárias, descartáveis, uma perda de tempo, podendo ser eliminadas: "existem matérias desnecessárias onde não aprendemos o que realmente precisamos, e assim perdemos tempo". Se a matéria não é necessária, é supérflua, algo que não trará benefícios ou lucro imediatos, podendo ser facilmente relegada. Percebe-se que as disciplinas são avaliadas a partir dos interesses individuais, de projeções que giram em torno da quantidade de benefícios proporcionados, como mostra o seguinte trecho: "Matemática (...) com essa matéria podemos fazer muitas coisas". Quem parece estar disposto a entrar nesse jogo, estabelecido a partir da lógica do uso e da conveniência, é um indivíduo que toma suas ações enquanto meios capazes de atingir uma finalidade específica, tratando os outros, os artefatos e a si mesmo como meras escadas rolantes. Se trazem benefícios e qualquer possibilidade de lucro, então são importantes e boas, devendo ser mantidas no Ensino Médio.

Essa perspectiva de ação nos remete aos imperativos hipotético e categórico kantianos. 0 "imperativo" foi um termo engendrado por Kant, empregado no sentido de mandamento. Na segunda seção do livro Fundamentação da metafísica dos costumes, o filósofo apresenta a sua definição mais recorrente: "um princípio objetivo, enquanto obrigante para uma vontade, chama-se um mandamento (da razão), e a fórmula do mandamento chama-se Imperativo (KANT, 2007, p. 48). Esclarecido esse termo, passemos a sua classificação. Os imperativos hipotéticos dizem respeito às ações pensadas enquanto meios para que finalidades específicas possam ser alcançadas. Os categóricos dizem respeito às ações cuja finalidade estão nelas mesmas, sem vistas em outra coisa, pois são necessárias em si mesmas (KANT, 2007).

Observando o modo como os alunos estão tratando as disciplinas curriculares, percebe-se que elas estão sendo vistas como meios para a obtenção de algo que lhes é interessante. Seguindo esse raciocínio, poder-se-ia dizer que, na perspectiva discente, ir à escola significa aprender conteúdos que serão futuramente úteis. No livro $P$ de Professor, Larrosa e Rechia (2018) fazem referência à exposição Um saber útil, ocorrida em 2014 e 2015 em Madrid. Segundo eles, quem separa os saberes em úteis e inúteis também separa as pessoas. Quem estabelece critérios de classificação também é capaz de estabelecer uma ordem social, hierarquizando as posições dos indivíduos dentro desse sistema.

Corroborando essa linha de pensamento, Silva sugere que "deter o privilégio de classificar significa também deter o privilégio de atribuir valor aos grupos assim classificados" (SILVA, 2014, p. 82). Mas, isso é agir conforme o imperativo hipotético e não o categórico. O indivíduo passa a categorizar os outros e a si mesmo pelo viés da usabilidade, como um meio para a obtenção de algo produtivo, uma vida que se coisifica. Um desrespeito à máxima kantiana se evidencia: "Age de tal maneira que uses a humanidade, tanto na tua pessoa como na pessoa de qualquer outro, sempre e simultaneamente como fim e nunca simplesmente como meio" (IBIDEM, p. 69). O filósofo atenta para essa questão do uso do outro como um meio e não como um fim em si mesmo e diz que isso não deve ser feito por aqueles que agem racionalmente (SILVA, 2014, p. 76).

Outra recorrência visualizada no material empírico diz respeito à organização temporal do ambiente escolar. As falas discentes deixam transparecer que um possível aumento da carga horária acarretaria em uma maior permanência nesse ambiente, obrigando os alunos a abrirem mão de outras atividades, como mostram os excertos selecionados: "Os alunos passaram mais tempo na escola e não terão 
muito tempo para a vida social"; "Vai complicar mais para o jovem sair, se divertir. Desfocar a cabeça em relação aos estudos"; "Porque os alunos ficariam maior parte do dia na escola que em casa"; "Porque nós, alunos, não íamos ter tempo para nada, nem para trabalhar e nem fazer o que a gente é acostumado"; "Querem aumentar as horas de estudo. Isso significa aturar os professores por mais tempo".

O que parece ser posto em xeque pelos alunos é o aumento da carga horária pretendido pela reforma do Ensino Médio, obrigando-os a permanecer na escola por mais tempo. Se isso for efetivado, eles precisarão readaptar suas vidas a fim de estarem em conformidade com as novas prescrições do governo. Os tempos aproveitados fora da sala de aula deverão ser remanejados, podendo indicar que "Os alunos passaram mais tempo na escola e não terão muito tempo para a vida social", dificultando "mais para o jovem sair, se divertir. Desfocar a cabeça em relação aos estudos". Isso "porque os alunos ficariam maior parte do dia na escola que em casa".

Essas enunciações trazem a ideia de que a vida discente não pode ser resumida ao ambiente escolar. Há atividades que devem ser feitas fora de seus muros, das quais esse espaço não dá conta, como a socialização, o lazer e o próprio ócio. Esse modo de perceber a escola vai ao encontro das observações feitas por Masschelein e Simons (2017). Conforme esses autores, a escola não é um local de socialização ou iniciação, sendo diferente de outros ambientes de aprendizagem: "O espaço escolar não se refere a um local de passagem ou de transição (do passado ao presente), nem a um espaço de iniciação ou de socialização (da família para a sociedade)" (MASSCHELEIN; SIMONS, 2017, p. 37). Pois a escola, priorizando a preparação para o mercado de trabalho, precisa se concentrar no desenvolvimento de coisas úteis, lucrativas, relegando as atividades ditas inúteis para além de seus muros. Porém, nesse contexto de cálculos necessários, algumas coisas acabam se perdendo. Conforme sugere Ordine (2016, p.18), "o olhar focado no objetivo a ser alcançado não permite mais desfrutar a alegria dos pequenos gestos cotidianos e descobrir a beleza que pulsa na nossa vida".

Quando um dos alunos diz, referindo-se à possibilidade de aumento da carga horária escolar, que ele "não ia ter tempo para nada, nem para trabalhar. E nem fazer o que a gente é acostumado", há indicação de um tempo sobrecarregado que dificultaria a realização de outras ações. Aqui a escola não é vista como um espaço que disponibiliza tempo, mas que o ocupa de determinada maneira, sobrepesando os alunos que têm outras ocupações em vista, podendo ser - na perspectiva discente - mais interessantes e relevantes do que a própria preparação para o futuro. Se todas as horas forem empregadas com vistas à empregabilidade, outras atividades deixarão de ser feitas, por falta de tempo. Como ler um livro, se não há tardes liberadas dos conteúdos escolares? Como instaurar um pensamento demorado sobre si, sobre o mundo, sobre aquilo que nos rodeia, nos afeta, nos desassossega, se não há tempo de sobra? Tratada como um meio e não como uma finalidade em si mesma, a escola passa a ser explorada enquanto um negócio, contrariando a perspectiva de Masschelein e Simons (2017, p.9) que a percebem enquanto skholé, "isto é, tempo livre para o estudo e a prática oferecida às pessoas que não tinham nenhum direito a ele de acordo com a ordem arcaica vigente na época".

Os filósofos Masschelein e Simons (2017), ao analisarem a escola contemporânea, tratam da desmotivação do aluno como um dos argumentos favoráveis à compreensão dessa instituição enquanto um espaço de aprendizagem estagnado, conservador, fora do seu tempo. Se a escola não consegue acompanhar as mudanças da contemporaneidade, os interesses dos alunos, das famílias, da mídia, do Estado e dos seus colaboradores, certamente que os alunos ficarão entediados com os 
conteúdos que os professores levarem para a sala de aula, tomados como ultrapassados. "Os jovens não gostam de ir à escola. Aprender não é divertido. O aprendizado é doloroso. Em geral, os professores são chatos e são um dreno do entusiasmo e da paixão pela vida dos alunos" (MASSCHELEIN; SIMONS, 2017, p. 16). Essas são algumas das acusações que confundem a compreensão da escola atual, devendo ser desconstruídas. Esses autores argumentam "que a escola não é sobre o bem-estar, e que falar em termos de (des) motivação é o sintoma infeliz de uma escola enlouquecida, que confunde atenção com terapia e gerar interesses com satisfazer necessidades" (IBIDEM, p. 17).

Desde que a escola foi institucionalizada, com "a imposição da obrigatoriedade escolar decretada pelos poderes públicos e sancionada pelas leis" (VARELA; URIA, 1992, p. 69), não há mais tempo a ser perdido com futilidades. Ou, nas palavras de Ordine, "o que não produz lucro é realmente considerado como um luxo supérfluo, como um obstáculo perigoso" (ORDINE, 2016, p. 13). O tempo precisa ser otimizado, preparando os alunos para o mercado de trabalho. A escola parece ter sido capturada pelo discurso econômico em que o sucesso ou fracasso futuro depende da habilidade dos alunos em serem empresários de si mesmos, enfatizando a empregabilidade. Seguindo nessa esteira, Masschelein e Simons (2017, p.88) apontam que "a 'empregabilidade', ao que parece, é a palavra em torno da qual o discurso e o pensamento sobre a escola são orientados hoje". Há metas a serem desenvolvidas e cumpridas no dia a dia escolar. O aluno, precisando dar conta de certo número de competências básicas a fim de assegurar um futuro promissor, sendo útil ao seu país, passa a ter o seu tempo escolar organizado com vistas no interesse de uma lógica empresarial.

\section{UMA SENDA POSSÍVEL}

Especialmente nos momentos de crise econômica, quando as tentações do utilitarismo e do egoísmo mais sinistro parecerem ser a única estrela e a única tábua de salvação, é preciso compreender que exatamente aquelas atividades que não servem para nada podem nos ajudar a escapar da prisão, a salvar-nos da asfixia, a transformar uma vida superficial, uma não vida, numa vida fluida e dinâmica, numa vida orientada pela curiositas em relação ao espírito e às coisas humanas. (ORDINE, 2016, p. 19)

Apresentamos, nesta seção, algumas reverberações que acreditamos serem pertinentes não para um desfecho final deste artigo, mas para o ensejo de outras análises, permitindo a abertura de outras veredas. Não propomos quaisquer verdades, apenas considerações possíveis obtidas a partir de um recorte espaço-temporal bastante específico. Tendo isso em vista, uma senda que acreditamos ter sido aqui aberta é o atravessamento do utilitarismo nas conduções das condutas neoliberais, como um elemento moderno revisitado e alterado conforme os próprios interesses da nova razão do mundo, servindo de padrão comportamental universalizante. Corroborando essa linha de pensamento, Dardot e Laval (2016, p.29) sustentam que o neoliberalismo vem se espalhando "a todos os países, a todos os setores da ação pública, a todos os domínios da vida social".

Se o neoliberalismo instala sua racionalidade nos mais variados âmbitos sociais, difundindo a necessidade de um cálculo utilitarista contínuo, sem deixar nada de fora, pode-se dizer que a vida humana é igualmente cooptada. Há, nesse caso, uma proliferação do imperativo hipotético kantiano, quando o ser humano acaba tratando os outros e a si mesmo como meros meios a serviço do mercado e dos próprios interesses mesquinhos. Uma pista que evidencia isso pode ser visualizada nas instituições escolares que seguem as prescrições da lógica neoliberal, onde o tempo é usado em consonância aos interesses do mercado, ocupando os discentes com aquilo que é tido como útil ao 
seu futuro profissional, não sobrando um tempo ocioso para uma busca desinteressada do conhecimento. Nesse sentido, pode-se dizer que a necessidade de serem instaurados cálculos utilitaristas continuamente é um dos rastros da nova razão do mundo que podem ser observados na escola atual.

Encerramos essa seção voltando-nos à epígrafe de abertura. O excerto de Nuccio Ordine (2016) nos remete à potencialidade daquilo que por muitos é avaliado como inútil, desinteressante, uma perda de tempo. À semelhança do autor, acreditamos que as coisas humanas devam ser vivificadas, permitindo-nos "desfrutar a alegria dos pequenos gestos cotidianos e descobrir a beleza que pulsa na nossa vida" (IBIDEM, p. 18). Colocando em xeque a forma neoliberal de se conduzir e ser conduzido na atualidade, resguardada pela maximização do cálculo de interesses, é possível instaurar fissuras no sistema, alimentar o supérfluo, experimentar uma vida mais fluida e menos narcísica. Em consonância a isso, atrevemo-nos a afirmar que o material explorado ao longo deste escrito não produzirá lucros, mas pode ser tratado por muitos como um luxo desprezível. Pois, mesmo não tendo qualquer pretensão de verdade ou estabelecendo julgamentos moralizantes, alguns podem tomá-lo como uma afronta ao modelo dominante, uma quimera a ser esquecida assim que tornada pública. De qualquer modo, seguimos motivadas a "experimentar exercícios que não são dirigidos desde o início para um resultado específico" (MASSCHELEIN; SIMONS, 2017, p. 162).

\section{REFERÊNCIAS}

ABBAGNANO, Nicola. Dicionário de Filosofia. São Paulo: Editora Martins Fontes, 2014.

BALL, Stephen. Educação Global S. A: novas redes políticas e o imaginário neoliberal. Ponta Grossa: UEPG, 2014.

BENTHAM, Jeremy. Uma introdução aos princípios da moral e da legislação. São Paulo: Abril Cultural, 1984.

BRASIL. Ministério da Educação. Secretaria de Educação Básica. Base Nacional Comum Curricular. Brasília: MEC, 2020.

BRASIL. Diretrizes Curriculares Nacionais Gerais da Educação Básica / Ministério da Educação. Secretaria de Educação Básica. Diretoria de Currículos e Educação Integral. Brasília: MEC, SEB, DICEI, 2018.

CASTRO, Edgardo. Vocabulário de Foucault - Um percurso pelos temas, conceitos e autores. Belo Horizonte: Autêntica Editora, 2009.

DARDOT, Pierre.; LAVAL, Christian. A nova razão do mundo. São Paulo: Boitempo, 2016.

FOUCAULT, Michel. A arqueologia do saber. Rio de Janeiro: Forense Universitária, 2009.

FOUCAULT, Michel. Vigar e punir: nascimento da prisão. Petrópolis, RJ: Vozes, 2009a.

KANT, Immanuel. Fundamentação da metafísica dos costumes. Edições 70, 2007.

LARROSA, Jorge; RECHIA, Karen. P de Professor. São Carlos: Pedro \& João Editores, 2018.

LENOIR, Yves. O utilitarismo de assalto às ciências da educação. Educar em Revista, Curitiba, Brasil, n. 61, p. 159-167, jul./set. 2016. 
MASSCHELEIN, Jean; SIMONS, Maarten. Em defesa da escola: uma questão pública. Belo Horizonte: Autêntica Editora, 2017.

ORDINE, Nuccio. A utilidade do inútil: um manifesto. Rio de Janeiro: Zahar, 2016.

PARAÍSO, Marlucy Alves. Metodologias de pesquisas pós-críticas em educação e currículo: trajetórias, pressupostos, procedimentos e estratégias analíticas. In: MEYER, Dagmar Estermann; PARAÍSO, Marlucy Alves (Org.). Metodologias Pós-críticas em educação. Belo Horizonte: Mazza Edições, 2014, p.25-47.

PEIXOTO, Paulo. Ética e regulação da pesquisa nas Ciências Sociais na sociedade do consentimento. Educação, Porto Alegre, v. 40, n. 2, p. 150-159, maio-ago. 2017.

REALE, Giovani; ANTISERI, Dario. História da Filosofia: do romantismo ao empiriocritismo. São Paulo: Paulus, 2007.

SIBILIA, Paula. Redes ou paredes: a escola em tempos de dispersão. Rio de Janeiro: Contraponto, 2012.

SILVA, Roberto Rafael Dias; SILVA, Denilson; VASQUES, Rosane. Políticas curriculares e financeirização da vida: elementos para uma agenda investigativa. Revista de Estudos Curriculares, v. 9, no 1, 2018, p.37-52.

SILVA, Tomaz Tadeu. A produção social da identidade e da diferença. In: SILVA, Tomaz Tadeu. Identidade e diferença. Petrópolis: Vozes, 2014, p.12-29.

SOUZA, Elisabete Gonçalves. Sociedade da informação e reestruturação produtiva: crítica à dimensão utilitarista do conhecimento. Transinformação, Campinas, v.23, n.3, p.219-226, set./dez., 2011.

VARELA, Julia; ALVAREZ-URIA, Fernando. A maquinaria escolar. Teoria \& Educação, São Paulo, n. 6, 1992, p.7-34.

VEIGA-NETO, Alfredo. Foucault \& a Educação. Belo Horizonte: Autêntica, 2007.

VEIGA-NETO, Alfredo; RECH, Tatiana Luiza. Esquecer Foucault? In: KIRCHOF, E. R.; WORTMANN, M. L.; COSTA, M. V. (Org.). Estudos culturais e educação: contingências, aventuras, dispersões. Canoas: Ed. ULBRA, 2015.

VILLAR, José Luiz M. O Utilitarismo e a Educação Profissional no Brasil. Por uma abordagem filosófica da História da Educação Profissional. Revista Sul-Americana de Filosofia e Educação, v.40, nov/2012-abr/2013, p. 120-134. 